\title{
Knowledge Management in a Software Development Organization: Identifying Tools, Processes and Benefits
}

\author{
Felipe Furtado \\ CESAR \\ Recife, PE, Brazil \\ fsfs@cesar.org.br
}

\author{
Gustavo Alexandre \\ CESAR \\ Recife, PE Brazil \\ ghsa@cesar.org.br
}

\author{
Nelson G. de Sá Leitão Júnior \\ Informatics Center \\ UFPE University and \\ CESAR \\ Recife, PE, Brazil \\ leitaojr@outlook.com
}

\author{
Ivaldir de Farias Junior \\ Informatics Center \\ UFPE University and \\ São Miguel College \\ Recife, PE, Brazil \\ ivaldirjr@gmail.com
}

\author{
Hermano P. de Moura \\ Informatics Center \\ UFPE University \\ Recife, PE, Brazil \\ hermano@cin.ufpe.br
}

Organizations usually seek for competitive differentials by investing money, time and effort usually in aspects such as information and communication technologies, lowering operating costs, improving productivity and the quality of their products. However, in late years, the importance that is given to the internal organizational knowledge has been increasing, either to understand the characteristics and demands of the competitive environment as well as to understand the needs associated with the organizations' processes.

This context demands an internal Knowledge Management approach in the organizations. Knowledge management (KM) can be defined as the process of capturing and utilizing the collective expertise of an organization in whatever the activities of its business.

This work has the objective of identifying the KM tools and processes used by a Brazilian private institution that creates products, processes, services and innovative companies using Information and Communication Technologies, as well as to identify the perceived benefits in the form of examples of success KM scenarios in different organizational contexts.

The data collection was carried out in November and December 2016 and had adhesion of 33 employees distributed in different areas: administrative, human resources, entrepreneurship, marketing, financial, operations, internal IT support, among others.

Existing initiatives at the institution were classified into processes and tools, and each of the participant answered the following question: "What tools / processes are used or have been used by your area for knowledge management?" The following results were found: Google Drive (94\%), e-mail lists (81\%), Slack (65\%), lessons learned meetings (65\%), Scrum retrospective meeting (50\%), Basecamp (38\%), PMO website (38\%), SVN (38\%), Dropbox (38\%), internal sites (31\%), Yammer $(25 \%)$, Wiki $(25 \%)$, CVS $(19 \%)$, internal social network (19\%), Slideshare (19\%), Youtube channel (16\%), Moodle (16\%), CRM (9\%), and others (41\%).

Among the most used tools, we can highlight the use of Google drive, email lists and Slack. Additionally, among the "Other" options, the following tools / processes were listed by the participants: internal meeting for organizational news, technical seminaries, lessons learned meetings through
Hangouts, Zoom, Skype and Confluence, internal mailing for organizational news, Mind Maps, Keepass, BI and Trello.

Although Google Drive has been pointed out by $94 \%$ of respondents, it has been widely used to capture and store knowledge or simply to perform backups of files. In some cases, it has worked only as a repository of reports, experiences, and techniques. There was no organizationally effective way for the remaining stages of the KM process: to refine, manage and disseminate knowledge. In a somewhat smaller proportion, but in a similar way, the e-mail lists have been used by most respondents in the sense of disseminating knowledge, but in a non-systematic way.

Regarding the main results achieved within the areas with the use of these tools and processes, we can cite some examples: support in the team allocation process to identify collaborators with certain technical knowledge, sharing information and building artifacts collaboratively, repository of documents in a structured way, facilitating the search and future analysis, either for legal necessity or as support in future similar projects, knowledge transfer in technologies and reduction of dependency on a single person who holds knowledge.

From the perception of participants, we conclude that, in general, the tools and processes used by the institution have helped the organization in the improvement of communication and diffusion of knowledge, but without a systematic process of knowledge management. The Institute is always in search for the improvement of the KM. Still, with the identified usage numbers of KM tools and processes, and the specific usage of some approaches by specific organizational departments, we noticed a tendency of dispersion.

Access to information in the organization is still difficult, but several participants indicate that it has already improved with the use of Slack. It is still perceived that there is a sense of silos, and the fact that some Non-Disclosure Agreements contracts with part of the customers, also prevent further sharing of information. Some specific knowledge is still in one or a few people, and when they leave, knowledge is lost. Future works include performing this survey in multiple organizations, to compare and analyze the results. 